\title{
A conversation with James Rothman
}

In the 70s and 80s, James Rothman of Yale University bucked all advice on how to do scientific experiments and broke open cells in order to study the way that vesicles are transported. His discovery of the machinery that orchestrates the budding, fusion, and transport of vesicles is key to organelle formation, nutrient uptake, and the secretion of most hormones and neurotransmitters in the body. For this work, Rothman (Figure 1) shared the 2013 Nobel Prize in Physiology or Medicine. The full interview, with vignettes about his first scientific experiments, what the next 10 years hold, and whether he'll ever run for public office, can be seen on the JCI website (http://www.jci.org/videos/cgms).

JCI: What were you like as a kid?

Rothman: I was playful, but I was also a nerd. My mother says that I didn't say anything at all until I was about three, and then I spoke in complete sentences. Otherwise, I think I was a pretty normal kid. My dad was a practicing pediatrician in a small town in Massachusetts, the only one for many miles around. My mom was a homemaker who was very much involved in his practice.

I always sort of knew I was going to be a scientist; there was a time I wanted to be a fireman, but it was very brief. I grew up in an era wherein technology, and especially physical sciences, was very important to all of us in daily ways. I remember the Cuban missile crisis and the fear of nuclear war, the space program, the transistor, the first radios, jet airplanes. It was a very dynamic time.

JCI: You ended up going to Yale to study physics, but then pivoted towards biology.

Rothman: I didn't know what physicists did or what they were, but it seemed like it would be nice to be one of them, so I headed in that direction. When I was in my second to last year in college, my dad said, "Really, you ought to have a look at biology. There are very few jobs for physicists." Of course, I immediately rejected that, because one of the first things you learn as a physics student is that physicists are really smart and mathematicians are even smarter, chemists are not really very smart, and biologists are outrageously stupid. And chemists - they're at least doing something that's physical, so they're socially acceptable, but biologists: don't go anywhere near that.

It took a little bit actually to overcome that prejudice, but out of respect for my dad, I went to my first lecture in a biology course since my freshman year in high school, and it was a complete revelation to me. It was instantaneous love.

JCI: Goodbye physics and hello medical school.

Rothman: I did go to medical school after college, which was an unusual thing to do with that kind of a pivot. In my case,

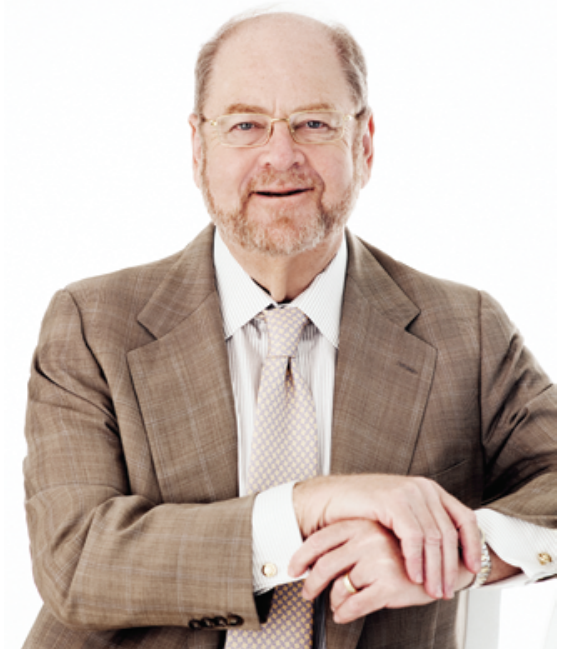

Figure 1. James Rothman on October 3, 2014. Image credit: Alena Soboleva.

I never really had any doubt that I was going to do research. But I didn't know what direction of biology to go in. I mean, I could have done something that would have been convenient and more related to physics, but my knowledge was so limited that I felt that any decision I made wouldn't be well reasoned and that I just needed a greater breadth. And so I went to medical school. I have about nine months left at Harvard Medical School. I think my mother would still like me to take a sabbatical to get my medical degree. I'm joking now, but actually that was true for quite some time. I had to explain to her that I actually was a real doctor of a sort.
In medical school, I just fell in love with what we now call vesicle transport. And this happened in my first year of medical school - there was a lecture in histology on the work of George Palade, who had just discovered these extraordinary events that went on within a cell. And it seemed to me, how could all this happen without a guiding hand? It registered with me as powerfully interesting, fundamental, and important. So later, when the time came to get serious about a long-term problem, which happened as I was doing my postdoctoral work, vesicle transport was really very clearly what I had in mind.

JCI: After your PhD with Eugene Kennedy in biochemistry on the assembly of lipid bilayers, how did you transition to the Harvey Lodish lab for your postdoc?

Rothman: I was about 25 years old when I finished my PhD, and I started getting offers to become an assistant professor, including in the Department of Biochemistry at Stanford. I had the choice of either going back and completing my last year of medical school or accepting a job as an independent faculty member - without doing a postdoc. It was a hard choice to curtail any opportunities in medicine, but I did ultimately make that choice. It was probably the most difficult professional decision I've ever made.

At the time, my strong feeling was that lipids were very interesting, but proteins probably were more versatile and more interesting, and I thought I'd start to work on membrane proteins. I really wanted to understand how proteins are synthesized and learn how to work with cell-free extracts.

I ultimately decided to do a postdoc. As I looked around, I found the ideal person just across the river, Harvey Lodish, who, at the time, was a young full professor: I think he was 35,36 . Things were a little bit different back then - rather than sending a formal letter, I got on the phone and I called him and he invited me over the next day. I don't think he had my CV or anything. I went looking for Professor Lodish. I'll never forget this as long as I live: I saw this very young-looking guy bent over the centrifuge. I said, "Have you seen Professor Lodish?" And then he pops up with a smile on his face and said, "I'm Harvey Lodish." It was the beginning of a great relationship. 
JCI: You then became a young assistant professor at Stanford with extraordinary, but dogma-rejecting ideas. How did you get funding and gather students?

Rothman: A lot of people were very discouraging about the cell-free approach I wanted to take. But, funding - I got plenty of funding at the time; it was never an issue. One of the reasons I went to Stanford was the fact that the senior faculty, despite the fact that it was probably illegal, pooled all their NIH funds into one pot. It was made clear to me that if I spent more than I brought in, that would be fine. Eventually, I would have to make it up to the department as I became more senior.

Somehow students then were maybe a little less career oriented than they are now. I had no trouble attracting students and fellows, precisely because the work was adventurous. They had a sense that you try to do what's important, you take a risk, and what are the consequences anyway? You might lose six months in the lab. People didn't think about things in such a careerist way back then.

JCI: When you started to have some success with these cell-free extracts, the atmosphere around the laboratory must have been pretty electric. Can you talk a little bit about that time?

Rothman: The first success in reconstitution in an extract was around 1980, through a rough and crude system. By around 1984, we had made a robust version of the cell-free assay. I'll never forget the day that Bill Balch (a former postdoc) came back from the electron microscope facility. For days I'd been imploring him to use EM to look for vesicles. I didn't think he was doing it, but then one day, he pulls out these electron micrographs and I just about fell on the floor because there were all of these beautiful vesicles budding off the Golgi and other membranes that we had isolated - they had no vesicles and they had returned to the morphology that George Palade described. But they had been resuscitated to life by a cytosolic extract and the source of energy, ATP. At that moment, I knew that we really had something important. I would say by 1993-1994, we had the principal answers in hand. That period of time, for me and for my lab, was just an extraordinary experience.

Now, in relation to what was going on in other labs, because actually there's several different lines of discovery in this field, they came together in various mergers at various times. Randy Schekman, within the same time span, had succeeded in identifying 23 genes that controlled secretion in yeast in various ways and in complex ways because the mutations he discovered complemented each other. He could map them crudely, but reverse genetics in yeast had not yet been invented by Botstein, Fink, and Davis. Randy's biggest issue was trying get the proteins out of his genes. The same was true for me, except I had an extract with proteins that I could fractionate, though it was hard to purify proteins, especially if there were 10 or 20 of them required at the same time.

Now, synaptosomes - the third line of approach - were much more narrowly configured. This other line of discovery was initiated by Richard Scheller and Tom Südhof, independently and working with other folks, especially Pietro De Camilli and Reinhard Jahn. They wanted to solve the problem of how synaptic vesicles fuse with the plasma membrane to release neurotransmitters and especially how release was controlled by calcium. They took a structure-based proteomics approach, whereas Randy and I took a function-based approach. When you have a mutation that affects a transport step or any process, it must've eliminated a component that was functionally required directly or indirectly. The same thing if you have a protein that's required in a cellfree extract. In a proteomic approach, you isolate the organelle, that synaptic vesicle, which was really just available for the first time, and Südhof and Scheller recognized that and tried to characterize the proteins that are in it because they had to be important in one or another aspect of the synaptic transmission process.

They identified these proteins one by one, taking them off of gels, microsequencing them. Essentially, they were able to anatomically localize them by cytochemical techniques and by fractionation in the vesicle, in the plasma membrane, or in the cytosol.

JCI: It wasn't a complete catalog, but it was an important catalog.

Rothman: Yes. So how did the three lines of discovery come together? Two of which were functionally based, one of which was structure based in the synaptic vesicle. It was guesswork as to which protein does what, if any of them do anything in particular.
The first protein important in vesicle transport that was identified functionally was a protein we discovered called NSF, N-ethylmaleimide-sensitive fusion protein, which we purified from our cellfree extracts; it was required somehow in membrane fusion. Then with Axel Ullrich at Genentech, we were able to clone it, and when we looked at the sequence, it was astonishing that it was identical to the sequence of one of Randy's sec genes called sec18. The sequence had been published, but nobody knew quite what the protein did. It was somehow needed for transport, but it was only a couple years later that Randy could establish it was needed in fusion.

That was a very important convergence because Randy and I and everyone realized, each from their own point of view, that there must be a universal set of machinery in the secretory pathway. Randy and I went on, in collaborative work, to find another protein that was in common between the pathways. The human gene could be placed in yeast, and it functioned as if it were a yeast gene. So we knew there was a huge commonality and that meant two things. It meant first, the pathway was universal, and secondly, it meant that our cell-free in vitro biochemistry was not an artifact. That was a huge coming together of yeast and animal genetics and biochemistry, and from that point on, they never separated.

JCI: If you had to do it all over again and you couldn't choose science or medicine, what do you think would have captivated you?

Rothman: I advise a lot of students at Yale now, sometimes undergraduates. As they get close to graduation, a typical question is, "I'm kind of uncertain; what should I do?"

And what I always ask them is, "If someone told you today you could never be a scientist, how would you feel?" And if they say, "I would find that kind of discouraging," I'd say, "You shouldn't be a scientist." But if someone says to me, "I would feel like someone just kicked me in the gut," which is the way it would have felt to me, then I say, "You should go into science no matter what, because you can't do anything else." And so, I think my answer is, I was going to be a scientist no matter what.

\section{Ushma S. Neill}

